\title{
Preliminary Examination of Reductive Tendencies in Art Understandings and Lesson-Planning of Pre-Service Teachers
}

\section{Georgianna Short}

\author{
Content Knowledge and Teaching Art
}

The degree to which teachers understand the subjects they teach has been questioned in recent years. As early as 1983, reports such as Nation at Risk: The Imperative for Educational Reform (1983) suggest teachers' deficient content knowledge may be a significant factor in the decline of what American students know. Since that time, subject areas such as physics, biology, and history have conducted studies to determine whether, and to what degree, their teachers lack adequate subject-matter knowledge (Hashweh, 1987; Wilson \& Wineburg, 1988; Doyle, 1989). In the visual arts however, similar studies do not exist (Kowalchuk, 1990).

\section{The Complexity of Works of Art}

It is surprising that teacher educators in the arts have not been more concerned with the content knowledge of prospective teachers. Adequate content knowledge is central to teaching and understanding works of art which convey the social and political climate, historical tradition, religiousphilosophical beliefs, and artistic conventions of their makers. Indeed, works of visual art have been described as cognitively complex by both experts and scholars in the field (Goodman, 1984; Koroscik, 1985). If students are to appreciate and understand this complexity, teachers should function much like experts in bringing broad content knowledge and deep understanding to their teaching.

Scholars and other recognized experts, for example, bring a variety of content knowledge and connection-making to bear in their search for understanding works of art. For example, consider the painting entitled Man on Horse by Italian artist Marino Marini (1910). Figure and horse in this work are said to represent the universal struggle of man with his basic instincts (de San Lazzaro, Read \& Waldberg, 1975). Although man is often unaware that he is engaged in this struggle, particular life events are said to bring the conflict to consciousness (de San Lazzaro et al., 1975). In the following passage, art historian and Marini expert de San Lazzaro (1975) weaves back and forth among considerations of subject matter, formal qualities, and symbolism (meaning) to explain this moment of awareness:

A wandering rider who advances in the wind and rain, stupefied, blinded by his huge shadow, like heroes deprived of reason, 
heroes of no one; or the riders whose limbs have been lopped off and who, savagely defying emptiness, sit on horses whose necks are flattened out in fear, and whose straining nostrils seem to exhale ashes. Marini insists on the dazed condition of a being condemned to struggle unremittingly, now on the vengeful awakening, the leap forward. The emotional charge manages to absorb itself in the internal structure of the work without breaking the line. Henceforward form, considered as light, is not victorious over the shadow or the wound; rather, the wound has taken on form, and in fact has become form. (pp. 26-27)

When formal qualities are considered together with descriptive information in ways such as this, formation of deeper understandings of works of art may be possible.

Now consider the following comments about the same painting made by two pre-service art teachers during the author's pilot study. "Ann" is a college senior majoring in art education, and "Don" is a post-baccalaureate student with a four-year degree in art and design from another institution. Each has completed the coursework required for teaching certification and is looking forward to student teaching.

Ann begins by stating that she does not understand the painting and thinks it would look better if it were changed:

I'd probably make it realistic. I'm a realistic painter. I don't rea!ly get into the abstract stuff. l'd probably have a brown horse ... brown horse ..... and have the human figure normal. And then l'd draw the blood, if there was any, around the horse.

Evidently, Ann presumes a painting "should" be realistic in nature, and if it is not, it should be changed. She acknowledges that she does not relate to "the abstract stuff" and does not see this as a limitation in her own thinking as a future art teacher.

Don's reaction was much stronger. He took an immediate dislike to the painting and stated his objections in this way:

I get turned off by [paintings like this] real quick because [of] the formal qualities of it . . . and I don't think in terms of design and composition it is real attractive. I think there are alot of ugly shapes in there ... I'm not too wild about the head ... but the horse is better, the brush strokes create the horse, whereas the outline creates the man. It doesn't seem to me that he worked it out before he started down.

Don was also interested in changing the painting:

Marilyn Zurmuehlen's Working Papers in Art Education 1993 
First, l'd change the angle of the horse. See what I mean? He's in profile. That's not very interesting. He should be placed on an angle with his rear-end angled off to the right. That would create a diagonal situation. Do you see? Then, it would work much better. Also, the angle of the man's shoulders would need to be changed to compliment the movement, not counteract it, and lead the eye to the head of the horse which is the point of interest in the piece.

Neither Ann nor Don asks the date of painting or the country in which it was made. Neither questions the media or method of execution, the artist's purpose or what his other works might look like. Their comments reveal limited knowledge of the work's internal qualities, and each seems uninterested in the painting's external context. Both are unconcerned with the meaning behind this work of art and seem unable to get beyond their personal standard of what a "good" painting should be. How will these views be translated into the classroom? Will Don insist that "correct" diagonals be the focus of students' work, and Ann permit only realistic subject matter?

\section{Reductive Bias}

Ann and Don seem to believe there is only one standard for "good" art. Each professes to know what that standard is and presumably would guide children accordingly. But this one-dimensional approach confines student learning and limits what may be understood about works of art. If these future teachers had the ability to access multiple perspectives when considering works of art, they could obtain a richness of meaning not accessible to them now. This wider viewpoint would strengthen their teaching and benefit students.

However, Ann and Don have a limited strategy. They have reduced complex subject-matter to a single point of view. Their oversimplification is deficient, may constitute misinformation and result in distorted student understanding. Some literature on learning identifies these overly reductive tendencies among teachers and learners as reductive bias (Feltovich, Spiro, \& Coulson, 1988, 1991; Coulson, Feltovich, Spiro, 1989). Reductive bias is defined as a "proclivity toward the strategic mismanagement of complexity involving various forms of oversimplification" (Feltovich et al., 1988, p. 10). If future teachers in any subject area suffer from reductive bias, it can be problematic for students. In the visual arts, where complex ideas and deep understandings are required, reductive tendencies should be of particular concern.

\section{Reductive Bias and Pre-Service Art Teachers}

The purpose of this research is to determine whether pre-service art teachers exhibit reductive bias in their understanding of, and teaching about, visual art exemplars. Do reductive tendencies manifest in teachers' talk about art, selection of works of art, and lesson-planning for students? What

Marilyn Zurmuehlen's Working Papers in Art Education 1993 
influence does background experience have on what is understood and taught about works of art?

\section{Methodology}

Eighteen pre-service teachers participated in the study. Participants varied in age and experience. All were in the final stages of their coursework, excluding student teaching.

A multiple-case study replication design, as suggested by Yin (1991), was utilized to determine the presence of reductive bias. Each case study was self-contained: distinct qualitative evidence was sought regarding the facts for each case. Conclusions for each case were then considered to be the information needing replication by other individual cases (Yin, 1991, p. 57).

Qualitative data were triangulated from interviews, unit/lesson plans, self-reports, personal biographies, and college transcripts. Interviews, unit/lesson plans, and self-reports each involved the use of a work or works of art. Pre-service teachers selected these work(s) of art from a comprehensive range of reproductions provided by the researcher. Degree of understanding was determined by coding ways in which works of art were discussed and used in lesson-planning (Lincoln \& Guba, 1985). If the presence of reductive bias was detected within a case study, evidence from self-reports, autobiography, and university transcript, was considered in determining whether, and in what ways, background experience may have influenced reductive thinking.

\section{Preliminary Findings}

Examination of case study data is progressing. Preliminary investigation indicates oversimplified reductive thinking characteristic of reductive bias exists among some pre-service art teachers. The following examples taken from the data illustrate contrasting ways in which reductive bias was evident in two pre-service teachers' interviews about lessonplanning. Each future teacher is an undergraduate and each is 24 years old.

Rachael. "Rachael," a college senior, selected King Tutankhamen and His Mother, an Egyptian wall mural, for one of her lessons. She stated that she had a strong background in Egyptian art and artifacts and would feel comfortable building a lesson around this particular exemplar. In her discussion of the mural, Rachael mentioned that both the hieroglyphics and distorted body positions were fundamental components of Egyptian art. However, for her lesson plan, she decided to ignore these key ideas, and focus instead on the patterns bordering the mural:

I would go into a series of lessons that focus on patterns. And I would have a series of different works that have patterns in it (sic) and I would want this to be one of them. I would describe what repetitive

Marilyn Zurmuehlen's Working Papers in Art Education 1993 
shapes and lines and patterns are. And I would just verbally tell them that, and then I would have them pick out from the other ones, repetitive patterns.... For the studio I would teach a mosaic and patterns. Their entire mosaic would be a pattern.

By focussing her lesson only on the patterns and repetitive shapes found in the Egyptian wall mural, Rachael reduces the rich content of Egyptian art to a study of patterns. She seems unaware that focussing only on patterns could limit what her students understand about Egyptian works of art and might foster the mistaken impression that repetitive pattern is the most significant aspect about the mural, King Tutankhamen and His Mother.

Because Rachael failed to mention patterns in her initial examination of the wall mural, it was unclear whether she considered repetitive patterns a key element in this particular exemplar and/or in Egyptian art generally. Therefore, in a following interview, Rachael was asked whether she thought Egyptian art was mostly about patterns. If so, whether she considered repetitive pattern the most important aspect in Egyptian art. She responded in the following way:

A: No, I think they [the Egyptians] were depicting life and after-life. Mainly after-life it seems like. Egyptian art . . . all I can think of is tombs, after-life, preparing for the after-life.

Q: O.K. But with this lesson, you are teaching students only about patterns. By doing that do you think students are likely to walk away thinking Egyptian art is only about patterns since that is the only thing you have presented?

A: Yes, I think they would. But I think I would talk about the history a little bit. Just like verbally say blah, blah, blah, this is Egyptian art and it's about . In this particular work it is about , and then go into my patterns. I would just say the history and go on and talk about patterns.

Rachael's response indicates that she does know something about ancient Egyptian religious belief and its relationship to works of art made at the time. She also seems to be aware that religious precepts were integral to works of art made in Egyptian culture. Despite this background knowledge, however, Rachael fails to mention anything on her own about Egyptian religious belief in her initial interview or subsequent planning of her lesson. Only after prompting is she able to recall the importance of life and after-life to the ancient Egyptians and, even then, she still does not seem to see the relevance of religious belief to the mural depicting King Tutankhamen and His Mother.

Alvin. Another pre-service teacher, "Alvin," also selected King Tutankhamen and His Mother for his lesson-planning. Alvin admitted during an interview that he knew little about the work but selected it because: 
It's kept my interest. I like the way they [the figures] both appear to be royalty, and I like the way he's standing on all these people over here. It's kind of symbolic. I also like it because they appear to be lovers, the way he is sitting in her lap and the way they're looking eye to eye. I find it interesting because one, he is sitting in her lap instead of it being the other way around. . . it seems to be a very unusual kind of relationship. I think that's interesting.

When asked how he would use this Egyptian mural in a lesson plan, Alvin explained:

I would focus on how relationships between men and women are represented in art. I would find a few more examples and would teach about different men and women and their relationships. I would end up with a studio on it. I'm not sure exactly what it would be. Maybe to create some kind of painting or drawing depicting a relationship between men and women and kind of leave that up to the students as long as it is very tasteful. Just see what they come up with. I would have guidelines and criteria as to what I did want to see in terms of the production, but as far as subject-matter and how it is presented, I would leave that up to the students.

Alvin appears unconcerned about his lack of familiarity with the Egyptian mural he will soon present to students. He seems to believe that an attitude of "anything goes" is appropriate in interpreting the subject-matter, and appears unconcerned about the accuracy of his explanation. Evidently it does not occur to Alvin that his own perception of a love relationship between the figures might not be an accurate representation of the scene depicted. He does not seem to understand or care that King Tutankhamen and His Mother might have a substantive meaning related to the history and religion of the culture and appears oblivious to the need for researching the topic. In essence, the focus of his lesson stems from personal perspective and reduces the artwork of an ancient culture to an erroneous interpretation based entirely on speculation.

Comparison of Rachael and Alvin. Both Alvin and Rachael selected the same Egyptian mural for their lesson-planning, yet neither of these preservice teachers dealt with the work of art in any substantive way. Alvin admitted to little knowledge about the work. He guessed about a possible meaning, and passed that guess on to his students as factual information. Rachael, while professing to have substantial background in Egyptian art, did not hesitate to plan a lesson which reduced the mural, King Tutankhamen and $\mathrm{His}$ Mother, to the single formal quality of patterns. Neither teacher seemed interested in providing any information outside their selected focus, leaving learners to believe that the Egyptian mural may be primarily about the unusual love relationship or that works of art from Egypt are primarily about patterns. Both impressions are erroneous, and grossly under-represent works of art created in ancient Egypt.

Marilyn Zurmuehlen's Working Papers in Art Education 1993 
Student understanding can be maximized through focussed, coherent, and integrated instruction containing accurate concepts, ideas, and principles (Prawat, 1989). Reliable subject-matter knowledge must then be connected together in meaningful ways for students (Nickerson, 1985; Perkins \& Simmons, 1988; Prawat, 1989). However, such instruction may not be forthcoming from future teachers whose subject-matter knowledge is oversimplified and whose domain understanding is shallow and fragmented.

A call has been issued to "reassert the importance of deep understandings of subject-matter knowledge" among future teachers (Barnes, 1989, p. 16). Research indicates that much of what teachers learn about the subjects they teach comes from their experiences as undergraduates (Grossman, 1988). "People form their impressions of art's importance and their ideas about art curriculum during their post-secondary education" (Getty, 1985, p. 73). Therefore, how subject matter is presented to and experienced by future teachers is critical.

Pre-service visual art teachers must engage in experiences which encourage them to develop deeper understandings appropriate to the complexity of visual art: With more adequate content knowledge and deeper understanding of the domain, pre-service teachers cannot help but be stronger and more successful in their future teaching. Experiences designed to strengthen and improve the content knowledge of future art teachers and cultivate their connection-making ability may be a matter for future consideration.

\section{References}

Barnes, H. (1989). Structuring knowledge for beginning teaching. In M.D. Reynolds (Ed.), Knowledge base for the beginning teacher. New York: Pergamon Press.

Coulson, R. L., Feltovich, P. J., \& Spiro, R. J. (1989). Foundations of a misunderstanding of the ultrastructural basis of myocardial failure: $A$ reciprocation network of oversimplifications. Journal of Medicine and Philosophy, 14, 109-146.

Di San Lazzaro. (1975). Homage to Marino Marini. New York: Tudor Publishing Co.

Doyle, W. (1989). Themes in teacher education research. In W. R. Houston (Ed.), Handbook of research on teacher education. New York: Macmillan.

Feltovich, P. J., Spiro, R. J., \& Coulson, R. L. (1988). The nature of conceptual understanding in biomedicine: The deep structure of complex ideas and the development of misconceptions (Tech. Rep. 
No. 440). Champaign: University of Illinois, Center for the Study of Reading.

Feltovich, P. J., Spiro, R. J., \& Coulson, R. L. (1991). Learning, teaching, and testing for complex conceptual understanding. (Tech. Rep. No. 6). Springfield: Southern Illinois University School of Medicine.

Getty Center for Education in the Arts (1985). Beyond creating: The place for art in America's schools.. J. Paul Getty Trust.

Goodman. (1984). Of mind and other matters. Cambridge: Harvard University Press.

Grossman, P. L. (1988). A study in contrast: Sources of pedagogical content knowledge for secondary English. Unpublished doctoral dissertation, Stanford University, Stanford, CA.

Hashweh, M. A. (1987). Effects of subject-matter knowledge in the teaching of biology and physics. Teaching and Teacher Education, 3 (2), 109120.

Koroscik, J. S., Desmond, K. K., \& Brandon, S. M. (1985). The effect of verbal contextual information in processing visual art. Studies in Art Education, $27(1), 12-23$.

Lincoln, Y. S., \& Guba, E. G. (1985). Naturalistic inquiry. London: Sage Publication.

Nickerson, R. S. (1985). Understanding understanding. American Journal of Education, 93, 201-239.

Perkins, D. N. \& Simmons, R. (1988). Patterns of misunderstanding: An integrative model for science, math, and programming. Review of Educational Research, 58 (3), 303-326.

Prawat, R. S. (1989). Promoting access to knowledge, strategy and disposition in students: A research synthesis. Review of Educational Research, 59 (1), 1-41.

Wilson, S. M., \& Wineburg, S. S. (1988). Peering at history through different lenses: The role of disciplinary perspectives in teaching history. Teachers College Record, 89 (4), 525-539.

Yin, R. K. (1991). Case study research: Design and methods. New York: Sage Publications 